\title{
Effect of Chromium VI on edible plants and their health risks: case of Radish (Raphanus sativus L.)
}

\author{
Bouhadi Mohammed ${ }^{1 *}$,Elkouali M'hammed'. Talbi Mohammed'. Ainane Tarik ${ }^{2}$ \\ ${ }^{1}$ LCAM, Faculty of Sciences Ben Msik, Hassan II University of Casablanca, BP 7955, Casablanca 20660, Morocco. \\ ${ }^{2}$ Superior School of Technology, University of Sultan MoulaySlimane, PB 170, Khenifra 54000 Morocco.
}

\begin{abstract}
Radish (raphanus sativus L) is a vegetable very rich in vitamin $\mathrm{C}$ and fiber, this plant belonging to the family Brassicacae characterized by their great capacity to accumulate heavy metals such as Chromium. The aim of our work is the study of the effect of Chromium VI on the morpho-physiological parameters of radish and the assessment of health risk related to the bioaccumulation of $\mathrm{Cr}$ in the edible parts. The plantation of radish was made on a soil artificially contaminated by 4 concentrations of $\mathrm{Cr}(\mathrm{VI})$ $(10,20,40$ and 60ppm). After comparing the results obtained with the results of non-contaminated soil, it is observed that the $\mathrm{Cr}$ affects negatively the growth, yield and the content of chlorophyll, On the other hand, it is noticed that there is a slight increase of sugars, proteins and Proline content with the increase of CrVI concentration in the soil, we can explain this increase by the development of defense mechanisms by the radish plant against the stress caused by CrVI. Regarding the bioaccumulation of $\mathrm{Cr}$ we found that the concentration of $\mathrm{Cr}$ in different parts of radish is too high compared to the recommended daily dose $(120 \mu \mathrm{g})$, so it is not recommended to consume radish grown in areas contaminated by $\mathrm{Cr}$.
\end{abstract}

\section{Introduction}

The human and industrial activities have led to contamination of soils by various pollutants such as heavy metals, contamination of agricultural soils leads to losses in agricultural production and yield, and an hazardous effects on humain and animals health. Large soils all over the world are contaminated with heavy metals [1], the strong global demand for agricultural production can lead to use the contaminated or marginal soils and increase the risk of food contamination, each metal act in a different way depending on their role in cell metabolism. Microelements, such as zinc, are essential and participate in many physiological processes [2]. However, at optimal doses they are highly toxic and inhibit plant growth. Heavy metals such as chromium are toxic even at low concentrations [3]. The main sources of chromium contamination in leather processing, landfill leachate, Anthropogenic activities, industrial effluents, automobile exhausts, waste incinerators, metal plating and finishing operations, pesticides and fertilizers manufacturing, cement factories, wood processing, metallization, oxidative dyeing, metal finishing, tobacco emissions, acid manufacture chromic, cement plants and paper production [1, 4, 5]. metal stress-induced reductions in plant growth parameters may be ascribed to low water potential, nutritional imbalance, and reactive oxygen species (ROS) mediated oxidative stress [6]. [7] argued that plants exposed to high concentrations of trace elements synthesized less chlorophylls, carotenoids, and other photosynthetic pigments. In addition, as a self-defense mechanism, plants have antioxidant systems to remove ROS. However, in the case of severe toxicity, this defense system may not be able to mitigate the toxic effects that have resulted in reduced plant functioning and normal growth [8]. Some edible plants, including family of Brassica plants, are characterized for their ability to accumulate large quantities of heavy metals such as radish. This has led to the search for species that can be used for phytoremediation of sole, with the following main features [9] (i) the ability to accumulate heavy metals in non-edible parts; (ii) tolerance to high doses of metals; (iii) rapid growth and high accumulation biomass; (iv) easy to grow as an agricultural crop and easily harvested.

In this study, we evaluated the effect of chromium metal concentrations (10 to $60 \mathrm{ppm}$ ) on growth parameters, chlorophyll content, TSS content, proteins content and proline content of Radish (Raphanus sativus L.)

\section{Materials and Methods}

\subsection{Germination seeds}

Dry seeds were washed with sodium hypochlorite $20 \%$ for $5 \mathrm{~min}$, and then rinsed with distilled water. The seeds were placed on double layered the seeds were placed glass Petri dishes with double layer filter papers, soaked with $15 \mathrm{ml}$ of $\mathrm{H} 2 \mathrm{O}$ for the control and for the treatment soaked with $5 \mathrm{ml}$ of chromium solution [10].

\footnotetext{
* Corresponding author: hbouhadi5@gmail.com
} 


\subsection{Growth parameters}

The Radish plants were harvested after 1 month. The plants were oven dried at $80^{\circ} \mathrm{C}$ for $24 \mathrm{~h}$ to determine the dry weight of root, shoot and hypocotyl of radish. The content of chlorophyll was estimated using the method of [11]. Pigment concentrations are expressed as $\mathrm{mg} / \mathrm{g}$ FW (Fresh Weight).

\subsection{Chlorophyll content}

Leaf pigment contents including chlorophyll a andb, were extracted as described by [11].160 mg leaf samples were broyed in $4 \mathrm{ml}$ of acetone $(80 \%)$. The mixture was centrifuged for $10 \mathrm{~min}$ at $5000 \times \mathrm{g}$, and the absorbance ofthe supernatant was noted at 662 and $645 \mathrm{~nm}$ using a UV-Vis spectrophotometer (Lambda 25, PerkinElmer, Inc. USA).The pigment contents were calculated using theequations and coefficients given by [11].

$$
\begin{gathered}
\text { Chlorophyll a }(\mathrm{mg} / \mathrm{g})=11,24 \times \mathrm{DO}_{662}-2,04 \times \mathrm{DO}_{645} \\
\text { Chlorophyll } b(\mathrm{mg} / \mathrm{g})=20,13 \times \mathrm{DO}_{645}-4,19 \times \mathrm{DO} \mathrm{O}_{662} \\
\text { Total chlorophyll }=\mathrm{Chl} a+\mathrm{Chl} b
\end{gathered}
$$

The pigment fractions were calculated as mg g-1 fresh leaf weight.

\subsection{Total soluble sugars (TSS) content}

Total soluble sugars (TSS) were estimation by phenol sulfuric acid method [12]. The samples were measured spectrophotometrically at $485 \mathrm{~nm}$ by spectrophotometer (Palo Alto, California, USA). we used D-glucose as a standard.

\subsection{Proteins content}

Protein content in plant $(50 \mathrm{mg})$ was determined by using BSA as standard protein following the method of [13].

\subsection{Proline content}

Proline content in Radish plant (250 mg FW) was measured by spectrophotometer (Palo Alto, California, USA) according to the method of [14]. A standard curve was obtained from known concentrations of proline.

\subsection{Chromium accumulation}

The standardized color method [15] was used to determine the concentration of $\mathrm{Cr}$ (VI) which forms a red-violet complex measured by spectrophotometry at $540 \mathrm{~nm}$ using a JENWAY 6300 spectrophotometer with 1.5-diphnylcarbazide (DPC).

\subsection{Statistical analysis}

All the measurements were triplicates. The analysis of variance (ANOVA) was carried out using a version 24 of
SPSS and by Tukey's post-hoc test between treatment means [16].

\section{Results and Discussion}

\subsection{Germination seeds}

The chromium effect on radish seeds germination was shown in Fig. 1. Our results showed a decrease in germination rate by $1.65 \%, 3.3 \%, 13.3 \%$ and $38.3 \%$ for $10 \mathrm{ppm}, 20 \mathrm{ppm}, 40 \mathrm{ppm}$, and $60 \mathrm{ppm}$ of Chromium respectively, as compared to control plant.

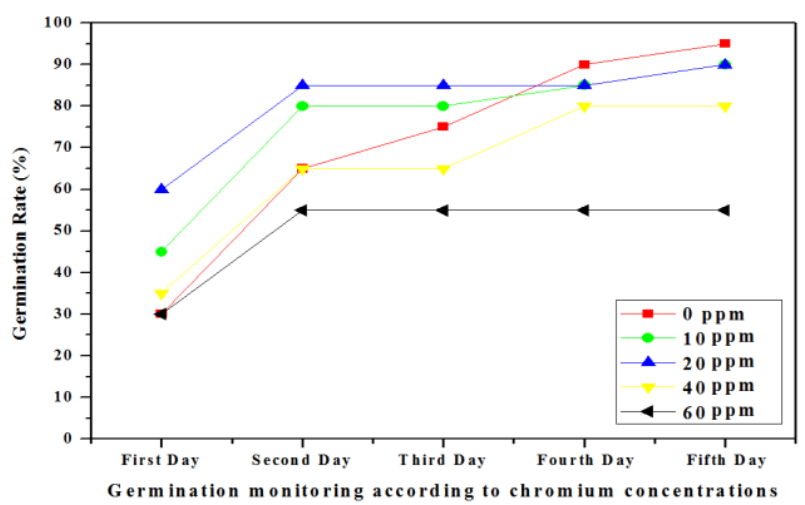

Fig. 1 Germination rate of radish seeds exposure to Chromium

\subsection{Growth parameters and Chlorophyll content}

The results showed that chromium have a harmful effect on growth parameters, chlorophyll content, TSS content, proteins rate and proline content Table 1 . In general, chlorophyll content decrease by $23 \%, 41 \%, 67 \%$, and $75 \%$ for $10 \mathrm{ppm}, 20 \mathrm{ppm}, 40 \mathrm{ppm}$, and $60 \mathrm{ppm}$ of chromium respectively, as compared to control plant.

The dry weight of shoot biomass of Raphanus sativus was influenced by the chromium, the metal caused a reduction of about $3 \%, 6 \%, 25 \%, 66.5 \%$ and in presence of $10 \mathrm{ppm}, 20 \mathrm{ppm}, 40 \mathrm{ppm}$ and $60 \mathrm{ppm}$ respectively, as compared to control plant. The dry weight of root of Raphanus sativus was affected by the metal.

The DW of root decreased by $25 \%, 41 \%, 83 \%, 91 \%$ and in presence of 10ppm, 20ppm, 40ppm and 60ppm respectively, as compared to control plant.

The dry weight of hypocotyl was affected by the chromium, the metal caused a reduction of about $2 \%$, $5.3 \%, 55.7 \%, 79 \%$ for $10 \mathrm{ppm}, 20 \mathrm{ppm}, 40 \mathrm{ppm}$ and $600 \mathrm{ppm}$ of metal respectively, as compared to control plant. In addition, However, we observed that TTS, total proteins and proline in Radish an increased slightly with the elevation of $\mathrm{Cr}(\mathrm{VI})$ concentration. 
Table 1 Chlorophyll content, dry weight of shoot, root hypocotyl, TSS content, proteins and proline content of Radish plant

\begin{tabular}{lccccc}
\hline Parameter & \multicolumn{4}{c}{$\mathrm{Cr}(\mathrm{ppm})$} & \\
\hline Treatment & Control & 10 & 20 & 40 & 60 \\
Chl a $+\mathrm{b}$ & $12.619 \pm 0.003$ & $9.716 \pm 0.02$ & $7.446 \pm 0.05$ & $4.164 \pm 0.045$ & $3.154 \pm 0.06$ \\
Shoot (g/plant) & $0.74 \pm 0.002$ & $0.72 \pm 0.01$ & $0.70 \pm 0.001$ & $0.55 \pm 0.013$ & $0.33 \pm 0.005$ \\
Root (g/plant) & $0.12 \pm 0.045$ & $0.09 \pm 0.12$ & $0.07 \pm 0.46$ & $0.02 \pm 0.001$ & $0.01 \pm 0.03$ \\
Hypocotyl DW(g/plant) & $0.95 \pm 0.1$ & $0.93 \pm 0.07$ & $0.90 \pm 0.057$ & $0.42 \pm 0.006$ & $0.20 \pm 0.08$ \\
total sugars (mg/g FW) & $0.176 \pm 0.04$ & $0.182 \pm 0.075$ & $0.190 \pm 0.8$ & $0.209 \pm 0.165$ & $0.219 \pm 0.065$ \\
Proteins (mg/g FW) & $5.16 \pm 0.12$ & $5.31 \pm 0.104$ & $5.43 \pm 0.04$ & $6.15 \pm 0.065$ & $6.3 \pm 0.08$ \\
Proline (mg/g FW) & $0.23 \pm 0.156$ & $0.245 \pm 0.05$ & $0.253 \pm 0.084$ & $0.287 \pm 0.07$ & $0.306 \pm 0.052$ \\
\hline
\end{tabular}

protein and proline respectively compared to the control

\subsection{Total sugars, Proteins and Proline content}

The results in Table 1 showed that exposure of radish plants to chromium slightly increases the production of soluble sugars, protein and proline. this increase is proportional to the increase in chromium concentration in the culture medium. it can be noted that the maximum production is recorded at the high chromium dose (60ppm) with an increase of $24 \%, 22 \%, 33 \%$ for SST,

Table 2 Chromium accumulation in shoot and root of Radish (Raphanus sativus)

\begin{tabular}{lccccc}
\hline Part & \multicolumn{4}{c}{ Treatment } \\
\hline & Control & $10 \mathrm{ppm}$ & $20 \mathrm{ppm}$ & $40 \mathrm{ppm}$ & $60 \mathrm{pmm}$ \\
Shoot & 0 & $0.47 \pm 0.003$ & $1.2 \pm 0.01$ & $1.5 \pm 0.021$ & $2.2 \pm 0.02$ \\
Root & 0 & $7.5 \pm 0.01$ & $16 \pm 0.05$ & $19 \pm 0.035$ & $21 \pm 0.04$ \\
\hline
\end{tabular}

The germination step is the first exchange interface with the surrounding medium and accordingly it is relatively sensitive to changing environmental conditions [17]. The present study showed that the Chromium metal reduced the germination rate, chlorophyll content, root and shoot dry weight of Radish (Raphanus sativus) as compared to control plant. These results correspond with that of [18] who observed that Chromium decreased the rate germination of Alfalfa seeds (Medicago sativa L.) by more than $50 \%$ and decrease the root and shoot weight Alfalfa plant. In addition [19] reported that the heavy metals reduced the root elongation of lettuce, broccoli, tomato and radish plant. However [20] noted that the germination of Coronilla varia was decreased by $\mathrm{Ni}, \mathrm{Cu}$, and $\mathrm{Cd}$. and the inhibitory effect on the belowground growth was greater than on the aboveground growth. [21] observed that the $\mathrm{Cd} 2+$ reduced the shoot and root dry weight of Okmass plants and decreased the Chlorophyll a (Chl.a) content. [22] noted that Exposure to $\mathrm{Cd}$ decreased the transcription levels of three upstream genes in the Chl biosynthesis pathway in leaf of Arabidopsis, The damage induced by toxic amounts of heavy metals has been attributed to different causes that usually act together, and can include direct metal damage and indirectly via induced oxidative stress [23]. reported effects include reduction in chlorophyll, altered water balance, decreases activity of various enzymes, stomatal closure, slowing down of photosynthesis rate and reduced uptake of essential mineral nutrients [1]. Soluble sugars are major products of photosynthesis and a main osmoregulation substance. Our results showed a slightly increase in soluble sugar with the elevation of Cr. [24] reported that the total proteins, soluble sugars,

\subsection{Chromium accumulation}

The variability of metal concentrations affected the chromium accumulation, Table 2 Showed that the accumulation in tissues increases with the increase of chromium concentrations in soil.

and malondialdehyde in T. angustifolia increased when the concentration of $\mathrm{Cr}$ (VI) increased from 9 to $30 \mathrm{mg}$ L-1. Accumulated total soluble sugars act as osmolytes to protect cells from damage and maintain the original physiological processes [25]. The total proteins in Raphanus sativus increased slightly with the increase of chromium concentrations. This may be that the oxidative stress caused by chromium metal induced an activation of enzyme activity in Raphanus sativus. Some studies also showed that some polypeptides (like phytochelatins and metallothioneins), which can bind with heavy metals to reduce their toxicity, can be synthesized by plants [26]. The increase in total soluble protein content under heavy metal stress may be related to the induced synthesis of stress proteins such as enzymes involved in Krebs cycle, glutathione and phytochelatin biosynthesis and some heat shock proteins [27]. The results of [28] showed that the heavy metals (lead, chromium, nickel, cadmium, zinc) affected the growth and performance of common bean (Phaseolus vulgaris L. cv. Nebraska), all heavy metals lowered the leaf contents of the photosynthetic pigments (chlorophyll a, b and carotenoids), also chemical analysis of carbohydrates showed increases in the contents of reducing sugars and total soluble sugars, and proteins content in response to heavy metals. In addition we reported that root of radish accumulated more of chromium than the leaves. The study of [29] revealed that as the contamination level increased significant reductions were observed in biomass, photosynthetic rate and chlorophyll $\mathrm{a}$ and $\mathrm{b}$ contents as compared to control plants. However, plant's stress tolerance mechanisms, including proline content and activity of antioxidant enzyme increased under different treatments. [30] observed an increase in proline 
concentration in roots and shoots that was triggered by $\mathrm{Cu}$ and $\mathrm{Cd}$ exposure was partly reversed. [31] Several species from the Brassica genus are very important agricultural crops in different parts of the world and are also known to be heavy metal accumulators. Cr-tolerant plants generally accumulated higher $\mathrm{Cr}$ concentrations in their roots than in their leaves [32]. Finally, we can concluded that the most of the absorbed chromium was accumulated in the roots of Radish, and small portions of $\mathrm{Cr}$ were transported to the rest of the plant by active transportation.

\section{Conclusion}

The present study revealed that growth parameters and chlorophyll contents were reduced under the influence of chromium treatments, while other parameters such as total soluble sugar, proteins content and proline content were slightly increased under similar conditions. Data indicated that Radis is moderately tolerant to chromium. it's could possibly be used with success in polluted soils and the extraction of heavy metals could be maintained at satisfying levels.

\section{References}

1. P.C. Nagajyoti, K.D. Lee, T.V.M. Sreekanth, Heavy metals, occurrence and toxicity for plants: a review. Environmental chemistry letters, 8(3), 1(2010)

2. Z.L He., X.E.Yang, P.J. Stoffella, Trace elements in agroecosystems and impacts on the environment. Journal of Trace elements in Medicine and Biology, 19(2-3), 125-140. (2005)

3. H.Marschner, Marschner's mineral nutrition of higher plants. Academic press. (2011)

4. S. Kaur, M.R. Kamli, \& A. Ali, Role of arsenic and its resistance in nature. Canadian Journal of Microbiology, 57(10), 769-774. (2011)

5. S. Afshan, S. Ali, S.A. Bharwana, M. Rizwan, M. Farid, F. Abbas, ... \& G.H. Abbasi, Citric acid enhances the phytoextraction of chromium, plant growth, and photosynthesis by alleviating the oxidative damages in Brassica napus L. Environmental Science and Pollution Research, 22 (15), 11679-11689. (2015)

6. S.M. Prasad, R. Dwivedi, M. Zeeshan, Growth, photosynthetic electron transport, and antioxidant responses of young soybean seedlings to simultaneous exposure of nickel and UV-B stress. Photosynthetica, 43(2), 177-185. (2005)

7. T. Ghnaya, H. Zaier, R. Baioui, S. Sghaier, G. Lucchini, G.A. Sacchi, ... \& C. Abdelly, Implication of organic acids in the long-distance transport and the accumulation of lead in Sesuvium portulacastrum and Brassica juncea. Chemosphere, 90(4), 1449-1454. (2013)

8. L. Rastgoo, A.Alemzadeh, Biochemical responses of Gouan ('Aeluropus littoralis') to heavy metals stress. Australian Journal of Crop Science, 5(4), 375. (2011)
9. L. Marchiol, S. Assolari, P. Sacco, G. Zerbi, Phytoextraction of heavy metals by canola (Brassica napus) and radish (Raphanus sativus) grown on multicontaminated soil. Environmental Pollution, 132(1), 21-27. (2004)

10. M. BOUHADI, A. AINANE, E.L. M'hammed, M. TALBI, O. CHERIFI, A. EL YAACOUBI, \& T. AINANE, Role of the macroalgae Corallina officinalis in alleviating the toxicity of hexavalent chromium on Vicia faba L. Journal of Analytical Sciences and Applied Biotechnology, 1(2), 1-2 (2019).

11. H.K. Lichtenthaler Chlorophylls and carotenoids: pigments of photosynthetic biomembranes. In Methods in enzymology (Vol. 148, pp. 350-382). Academic Press. (1987)

12. M. Dubois, K.A. Gilles, J.K. Hamilton, P.T. Rebers, F. Smith, Colorimetric method for determination of sugars and related substances. Analytical chemistry, 28 (3), 350-356. (1956)

13. O.H. Lowry, N.J. Rosebrough, A.L. Farr, R.J. Randall, Protein measurement with the Folin phenol reagent. Journal of biological chemistry, 193, 265275. (1951)

14. L.S. Bates, R.P. Waldren, I.D. Teare, Rapid determination of free proline for water-stress studies. Plant and soil, 39 (1), 205-207. (1973)

15. L.S. Clesceri, A.E. Greenberg, A.D. Eaton, Standard Methods for the Examination of Water and Wastewater, A. P. H. Association, Washington. 366. (1998)

16. A. Khadraji, M. Bouhadi, and C. Ghoulam, (2020). Effect of Soil Available Phosphorus Levels on Chickpea(Cicer arietinum L.) -

Rhizobia Symbiotic Association. Legume Research. 43(6): 878-883.

17. R. Solanki, R. Dhankhar, (2011) Biochemical changes and adaptive strategies of plants under heavy metal stress. Biologia, 66(2), 195-204.

18. J.R. Peralta, J.L. Gardea-Torresdey, K.J. Tiemann, E.Gomez, S. Arteaga, E. Rascon, J.G. Parsons, Uptake and effects of five heavy metals on seed germination and plant growth in alfalfa (Medicago sativa L.). Bulletin of Environmental Contamination and toxicology, 66(6), 727-734. (2001)

19. M. Di Salvatore, A.M. Carafa, G. Carratù, Assessment of heavy metals phytotoxicity using seed germination and root elongation tests: a comparison of two growth substrates. Chemosphere, 73 (9), 1461-1464. (2008)

20. J. Bae, D.L. Benoit, A.K. Watson, Effect of heavy metals on seed germination and seedling growth of common ragweed and roadside ground cover legumes. Environmental pollution, 213, 112-118. (2016)

21. S. Gul, M.F. Nawaz, M. Azeem, Interactive effects of salinity and heavy metal stress on ecophysiological responses of two maize (Zea mays 
L.) cultivars. FUUAST Journal of Biology, 6(1), 8187. (2016)

22. Y.Y. Wang, Y. Wang, G.Z. Li, L. Hao, Salicylic acid-altering Arabidopsis plant response to cadmium exposure: Underlying mechanisms affecting antioxidation and photosynthesis-related processes. Ecotoxicology and environmental safety, 169, 645-653 (2019).

23. K. Viehweger, How plants cope with heavy metals. Botanical Studies, 55(1), 35. (2014)

24. Y.L. Chen, X.Q. Hong, H. He, H.W. Luo, Qian T.T. , R.Z. Li, ... \& H.Q. Yu, Biosorption of Cr (VI) by Typha angustifolia: mechanism and responses to heavy metal stress. Bioresource technology, 160, 89-92. (2014)

25. A.B. Jha, R.S. Dubey, Carbohydrate metabolism in growing rice seedlings under arsenic toxicity. Journal of plant physiology, 161(7), 867872. (2004)

26. N. Estrella-Gómez, D. Mendoza-Cózatl, R. MorenoSánchez, D.González-Mendoza , O. Zapata-Pérez , A. Martínez-Hernández, J.M. Santamaría., The Pbhyperaccumulator aquatic fern Salvinia minima Baker, responds to $\mathrm{Pb} 2+$ by increasing phytochelatins via changes in SmPCS expression and in phytochelatin synthase activity. Aquatic Toxicology, 91 (4), 320-328. (2009)

27. S. Mishra Srivastava, S.R.D. Tripathi, R. Kumar, C.S. Seth, D.K. Gupta, Lead detoxification by coontail (Ceratophyllum demersum L.) involves induction of phytochelatins and antioxidant system in response to its accumulation. Chemosphere, 65(6), 1027-1039. (2006)

28. N.F. Aldoobie, M.S. Beltagi, Physiological, biochemical and molecular responses of common bean (Phaseolus vulgaris L.) plants to heavy metals stress. African Journal of Biotechnology, 12 (29). (2013)

29. K.R. Sheetal, S.D. Singh, A. Anand, Prasad S., Heavy metal accumulation and effects on growth, biomass and physiological processes in mustard. Indian Journal of Plant Physiology, 21(2), 219-223. (2016)

30. V. Singh, B.N. Tripathi, \& V. Sharma, Interaction of $\mathrm{Mg}$ with heavy metals $(\mathrm{Cu}, \mathrm{Cd})$ in $T$. aestivum with special reference to oxidative and proline metabolism. Journal of plant research, 129(3), 487497. (2016)

31. M.P. Mourato, I.N. Moreira, I. Leitão, F.R. Pinto, J.R. Sales, L.L. Martins, Effect of heavy metals in plants of the genus Brassica. International journal of molecular sciences, 16(8), 17975-17998. (2015)

32. A. Sasmaz, E. Obek, H. Hasar, The accumulation of heavy metals in Typha latifolia L. grown in a stream carrying secondary effluent. ecological engineering, 33(3-4), 278-284. (2008) 